\title{
Introduction : Permanences et mutations spatiales dans la Hongrie en transition
}

\section{Simon Edelblutte}

\section{OpenEdition}

\section{Journals}

Édition électronique

URL : http://journals.openedition.org/rge/1801

DOI : $10.4000 / \mathrm{rge} .1801$

ISSN : 2108-6478

Éditeur

Association des géographes de l'Est

Édition imprimée

Date de publication : 1 janvier 2003

ISSN : 0035-3213

\section{Référence électronique}

Simon Edelblutte, «Introduction : Permanences et mutations spatiales dans la Hongrie en transition », Revue Géographique de l'Est [En ligne], vol. 43 / 1-2 | 2003, mis en ligne le 01 décembre 2010, consulté le 25 septembre 2020. URL : http://journals.openedition.org/rge/1801 ; DOI : https://doi.org/10.4000/ rge. 1801

Ce document a été généré automatiquement le 25 septembre 2020

Tous droits réservés 


\title{
Introduction : Permanences et mutations spatiales dans la Hongrie en transition
}

\author{
Simon Edelblutte
}

1 Pour la seconde fois en deux ans, la Revue Géographique de l'Est consacre un numéro à la Hongrie. Le premier $\left(n^{\circ} 4 / 2001\right)$ regroupait trois articles de géographie physique, celui-ci rassemble sept contributions de géographie humaine ${ }^{1}$. Ceci est d'autant plus remarquable pour notre revue que seulement quatre articles avaient concerné la Hongrie depuis la naissance de la RGE en $1961^{2}$. À quelques mois de l'entrée de ce pays dans l'Union Européenne (UE), les sept articles écrits par des chercheurs géographes hongrois des universités de Budapest, Pécs et Debrecen sont consacrés à des thèmes et espaces divers, mais tous reliés à la fois par la volonté de tenir compte de l'ancrage millénaire du pays au sein de l'Europe et par la problématique évidemment incontournable de la transition d'un régime communiste vers le monde capitaliste.

2 Les trois premiers articles ont une forte teneur géohistorique, reliant la problématique actuelle de la transition à l'histoire du territoire et de son organisation. À petite échelle, $\mathrm{K}$. Kocsis aborde les fluctuations très importantes du peuplement hongrois dans le bassin des Carpates. Peu de peuples ont ainsi vu leur espace national se dilater, puis se réduire aussi brutalement au début du $\mathrm{XX}^{\mathrm{e}}$ siècle, laissant de très fortes minorités magyares audelà des frontières nationales et, en retour, poussant à l'homogénéisation du peuplement sur le territoire resté hongrois. L'intégration à l'UE devrait largement participer au règlement de cette question des minorités magyares. À plus grande échelle, Z. Hajdú s'intéresse aux découpages administratifs internes du pays - en particulier à celui des comitats - évidemment largement influencés par les modifications frontalières évoquées dans le premier article. À l'heure de l'entrée dans l'UE, la volonté politique de créer, au-dessus des comitats, de grandes régions capables de rivaliser avec les autres régions européennes, est aujourd'hui affirmée. Dans le troisième article, F. Erdösi s'intéresse lui aussi à l'organisation régionale, mais par le biais des transports. Il montre comment, au cours de l'histoire hongroise, la mise en place du 
réseau ferré a, malgré des tentatives de contournement, toujours renforcé le rôle de Budapest et - à plus grande échelle - comment elle a pu aller jusqu'à provoquer des changements de chef-lieux de comitats.

3 Les deux articles suivants, se complétant largement, sont centrés sur la transition et ses conséquences. Conséquences spatiales à diverses échelles dans le cas de l'article de J. Nemes-Nagy qui, même s'il aborde des points sûrement déjà connus des lecteurs de la RGE, permet de replacer les autres articles dans un contexte plus large; conséquences socio-spatiales dans le cas de l'article de Z. Dövényi qui s'intéresse plus particulièrement au problème du chômage.

4 Enfin, les deux derniers articles sont des études de cas concernant les deux plus grandes villes de Hongrie : J. Szábo, T. Kiss et J. Lóki nous offrent un passionnante étude du potentiel récréatif des environs de Debrecen au moment du développement en Hongrie de la civilisation des loisirs, tandis que É. Izsák et F. Probáld évoquent, en liaison avec le développement de Budapest, la ville de banlieue de Budaörs, l'une des cités les plus dynamiques - démographiquement et économiquement - du pays depuis la transition.

\section{NOTES}

1. Les articles de ce numéro, soutenu par l'Académie des Sciences de Hongrie, ont été rassemblés par le Professeur G. Gabris de l'université Eötvös Loránd de Budapest. Le travail de traduction de l'anglais au français, d'adaptation des textes français, puis de reprise des figures sous Adobe Illustator a été effectué par l'équipe nancéienne de la RGE : V. Bertrand, E. Chiffre, M. Deshaies, S. Edelblutte, J. Mathieu et $\mathrm{S}$. Rosière. Les résumés ont été traduits en anglais par $\mathrm{C}$. Whiteman et en allemand par W.D. Sick.

2. ENYEDI György, L'agriculture hongroise : problèmes de régionalisation (chronique d'Europe centrale), n³/1964, Tome IV, p. 297-300.

GABRIS Gyula, Paléohydrologie tardiglaciaire et holocène en Hongrie d'après l'étude des méandres libres, $n^{\circ}$ 4/2001, Tome XLI, p. 149-156.

KERTESZ Adam, LOCZY Dénes, HUSZAR Tamas, Aridification : l'effet du changement climatique dans le Bassin Carpatique, $n^{\circ}$ 4/2001, Tome XLI, p. 141-148.

LEGER Michel, Un congrès en Hongrie (congrès et colloques), nº 2/1963, Tome III, p. 171-178.

NADASRI Istvàn, De la puszta hongroise de Nagyus à la colonie franco-lorraine de Triebswetter (1769-1801), $\mathrm{n}^{\circ}$ 1-2/1979, Tome XIX, p. 17-66.

ROSIERE Stéphane, Contribution à l'étude géographique des frontières : le cas de la Hongrie, $\mathrm{n}^{\circ}$ 4/1998, Tome XXXVIII, p. 159-168.

ZAMBO Laszlo, Corrosion d'origine microbienne sous les sols du karst du Nord-Est de la Hongrie, étude expérimentale, $n^{\circ}$ 4/2001, Tome XLI, p. 157-164. 


\section{AUTEUR}

\section{SIMON EDELBLUTTE}

Université de Nancy 2, BP 33-97 - 54015 Nancy Cedex, France - Simon.Edelblutte@univ-nancy2.fr 